\title{
Prevalence of physiological uptake in the pancreas on somatostatin receptor-based PET/CT: a systematic review and a meta-analysis
}

\author{
Sarah Boughdad ${ }^{1} \cdot$ Marie Meyer $^{1} \cdot$ John O. Prior ${ }^{1,2} \cdot$ Victor Fernandes $^{1} \cdot$ Gilles Allenbach $^{1} \cdot$ Christel Kamani $^{1}$. \\ Mario Jreige ${ }^{1} \cdot$ Domenico Albano $^{3} \cdot$ Francesco Bertagna $^{3} \cdot$ Marie Nicod-Lalonde $^{1} \cdot$ Niklaus Schaefer $^{1,2}$. \\ Giorgio Treglia ${ }^{1,2,4,5,6}$
}

Received: 13 March 2021 / Accepted: 7 May 2021 / Published online: 21 May 2021

(c) The Author(s) 2021

\begin{abstract}
Background Physiological focal radiopharmaceutical uptake in the head and uncinate process of the pancreas may be seen on somatostatin receptor-based PET/CT and might lead to false-positive results for neuroendocrine tumours (NETs). We aimed to perform a systematic review and a meta-analysis about the prevalence of this finding.

Methods We performed a comprehensive computer literature search across several databases until July 2020. Pooled prevalence of physiological focal uptake on somatostatin receptor-based PET/CT in the pancreas was calculated on a per-examination-based analysis and $95 \%$ confidence interval values $(95 \% \mathrm{CI})$ were reported.

Results Six studies (684 patients and 829 PET/CT scans) were included. The pooled prevalence of physiological uptake in the head and uncinate process of the pancreas on somatostatin receptor-based PET/CT imaging was 34\% (95\% CI 19.5-48.7\%) with average SUVmax values ranging from 5 to 12.6. Heterogeneity was seen across the selected studies.

Conclusions High radiopharmaceutical uptake in the head and uncinate process of the pancreas is frequent at somatostatin receptor-based PET/CT and it should be recognized by nuclear medicine physicians to prevent unnecessary additional investigations. In addition, next generation PET/CT tomographs might increase the prevalence of this finding.
\end{abstract}

Keywords Pancreas $\cdot$ PET/CT $\cdot$ PET $\cdot$ Somatostatin $\cdot$ Incidental $\cdot$ Meta-analysis $\cdot$ Systematic review

Giorgio Treglia

giorgio.treglia@eoc.ch

1 Department of Nuclear Medicine and Molecular Imaging, Lausanne University Hospital, Lausanne, Switzerland

2 Faculty of Biology and Medicine, University of Lausanne, Lausanne, Switzerland

3 Department of Nuclear Medicine, University of Brescia and Spedali Civili Brescia, Brescia, Italy

4 Clinic of Nuclear Medicine, Imaging Institute of Southern Switzerland, Ente Ospedaliero Cantonale, Via A. Gallino 12, 6500 Bellinzona, Switzerland

5 Academic Education, Research and Innovation Area, General Directorate, Ente Ospedaliero Cantonale, Bellinzona, Switzerland

6 Faculty of Biomedical Sciences, Università della Svizzera Italiana, Lugano, Switzerland

\section{Introduction}

Neuroendocrine tumors (NETs) originate from neuroendocrine cells and are more frequently located in small intestine and pancreas $[1,2]$. Recently, there has been an increase in the use of somatostatin receptor-based positron emission tomography/computed tomography (SSTR PET/CT) in the setting of NETs including pancreatic tumors $[3,4]$. The identification and localization of pancreatic NETs using SSTR PET/CT might affect patient medical and surgical management [2]. Physiological and intense radiopharmaceutical uptake in the head and uncinate process (UP) of the pancreas at SSTR PET/CT has been reported in the literature and this finding could lead to false-positive results, hence to additional investigations such as imaging or biopsies [5].

The increased radiopharmaceutical uptake in the head and UP of the pancreas seen on SSTR PET/CT can be explained by a higher density of cells expressing somatostatin receptors in these sites in comparison to the rest of the pancreatic gland [5, 6]. However, pancreatic NETs are sometimes 
located in the UP and focal radiopharmaceutical uptake in the UP should not always be dismissed as physiological.

Therefore, to establish the prevalence of physiological radiopharmaceutical uptake in the head and UP of the pancreas on SSTR PET/CT, we performed a systematic review and meta-analysis to provide useful data for nuclear medicine physicians and radiologists that could be used to better discuss diagnostic strategies when confronted to this finding.

\section{Methods}

\section{Search strategy}

A comprehensive computer literature search of PubMed/ MEDLINE, and Cochrane library databases was performed by two authors (SB and GT) to identify published articles that investigated the prevalence of physiological uptake in the pancreatic head and UP at SSTR PET/CT. A combination of the following terms was used for the search algorithm: ((DOTATOC) OR (DOTANOC) OR (DOTATATE) OR (DOTA) OR (somatostatin)) AND ((PET) OR (positron)) AND ((pancreas) OR (pancreatic)) AND ((physiological) OR (physiologic) OR (incidental) OR (normal) OR (false positive)). The literature search was updated until 31 July 2020.

\section{Study selection}

Original articles within the field of interest reporting the prevalence of physiological uptake in the pancreatic head and UP at SSTR PET/CT were eligible for inclusion. The exclusion criteria were as follow: (a) articles outside of the field of interest of this review; (b) case reports and small case series; (c) review articles, comments, letters, editorials, and conference proceedings. No language or date restrictions were used. The titles and abstracts of the recovered articles were reviewed independently by two researchers (SB and GT) according to the inclusion and exclusion criteria previously mentioned. Articles which appeared evidently ineligible were rejected. The full-length version of the remaining articles was independently reviewed by two researchers (SB and GT) to evaluate their eligibility for inclusion. Any disagreements over articles eligibility were resolved during a consensus meeting.

\section{Data extraction}

All the authors contributed to data extraction. Basic study information was collected for each eligible study that is authorship, year of publication, country, study design, number of patients recruited and mean patients age. The type of PET or PET/CT tomographs and radiotracer used as well as the prevalence of physiological uptake in the pancreatic head and UP detected on SSTR PET/CT were collected. In addition, the percentage of these findings found on additional evaluation with anatomical imaging, including magnetic resonance imaging (MRI) or contrast-enhanced computed tomography (CE-CT) was also reported.

\section{Statistical analysis}

Pooled prevalence of physiological uptake in the pancreatic head or UP detected on SSTR PET/CT, including 95\% confidence interval values $(95 \% \mathrm{CI})$, were calculated on a per-examination-based analysis. Inconsistency index $\left(I^{2}\right)$ was used to estimate heterogeneity; it describes the percentage of variation across studies that is due to heterogeneity and not chance. The Egger's test was used to assess publication bias [7]. Statistical analyses were done using StatsDirect software (Version 3, Birkenhead, UK).

\section{Quality assessment}

All the authors contributed to the quality assessment. The overall quality of the studies included in this systematic review was appraised based on the NIH National Heart, Lung and Blood Institute Study Quality Assessment Tools.

\section{Results}

\section{Literature search}

The comprehensive computer literature search from MEDLINE/PubMed and Cochrane library databases retrieved 154 articles. After applying the exclusion criteria previously mentioned, six original articles were selected and recovered in full-text version [8-13]. The detailed process of article selection is reported in Fig. 1. There were no additional articles found after a further screening of the references of those selected articles. Thus, 6 studies totaling 829 scans in 684 patients reported data on the prevalence of physiological uptake in the pancreas on SSTR PET/CT and were suitable for pooled analysis [8-13]. The characteristics of the studies included in this systematic review are showed in Tables 1, 2 and 3.

\section{Qualitative analysis (systematic review)}

The six articles assessing the prevalence of physiological uptake in the pancreas on SSTR PET/CT were published between 2011 and 2014 [8-13]. All those studies were retrospective and monocentric [8-13]. The quality of the included studies was judged as moderate using the selected quality assessment tool in all cases. Even though, PET/CT 
Research question: Prevalence of physiological uptake in the pancreas at somatostatin receptor PET

Search string: ((DOTANOC) OR (DOTATOC) OR (DOTATATE) OR (DOTA) OR (somatostatin)) AND ((PET) OR (positron)) AND ((pancreas) OR (pancreatic)) AND ((physiological) OR (physiologic) OR (incidental) OR (normal) OR (false positive))

Database screened: PubMed/MEDLINE and Cochrane library until July 31, 2020

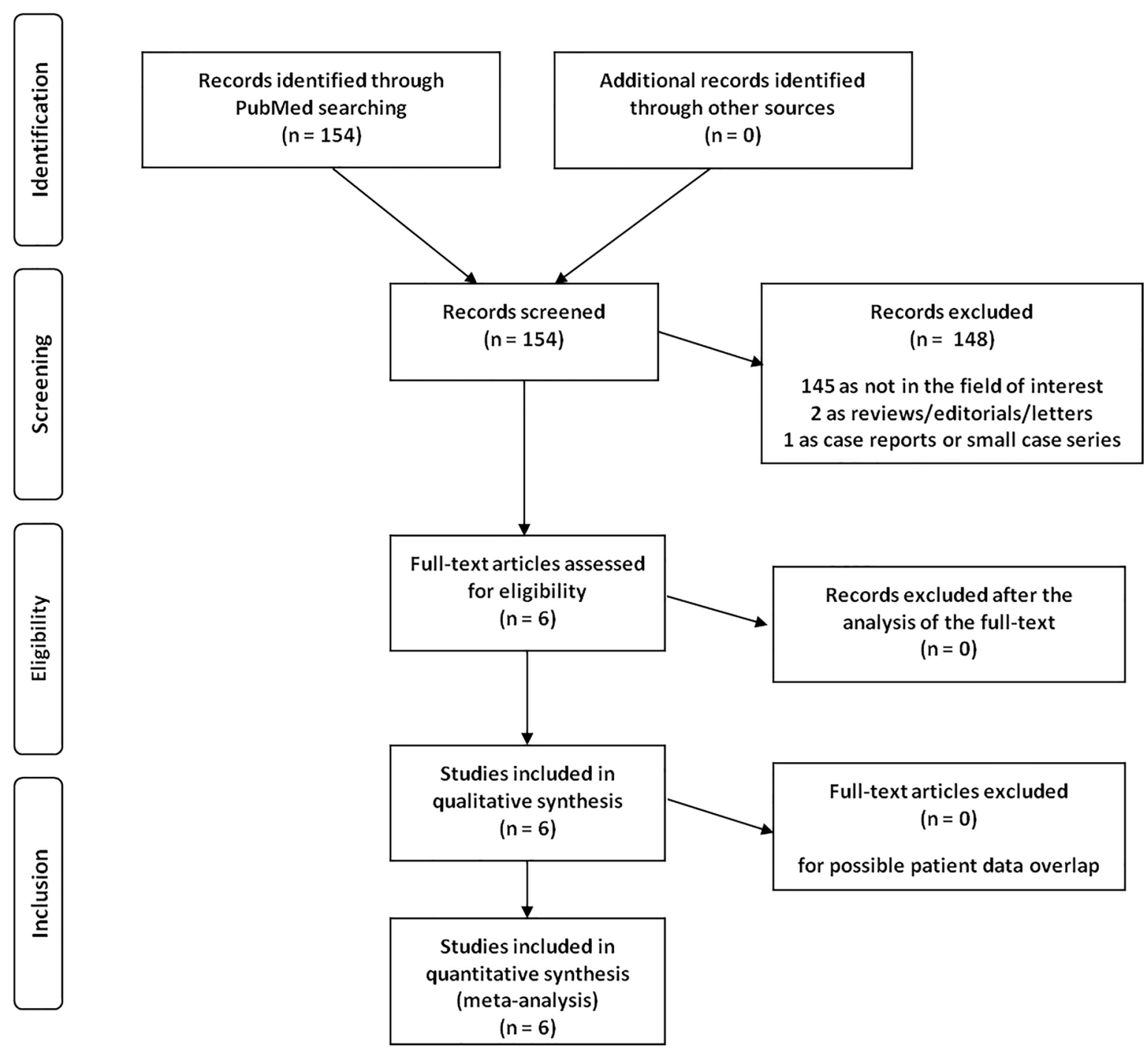

Fig. 1 Flowchart of the literature search

was performed in all studies, there was a lack of homogeneity between studies, beginning with differences in terms of radiotracers used $\left({ }^{68} \mathrm{Ga}\right.$-DOTATOC, ${ }^{68} \mathrm{Ga}$-DOTATATE or ${ }^{68}$ Ga-DOTANOC) (Table 2). The studied population also differed between studies. Most studies recruited patients with NETs except for one study by Kunikowska et al. studying the pancreatic uptake in a general population of patients referred for imaging using ${ }^{68}$ Ga-DOTATATE PET/
CT [8-13]. Average age of patients was $61.5 \pm 3.5$ years with a majority of male patients [8-13]. The prevalence of physiological radiopharmaceutical uptake in the pancreatic head and UP on SSTR PET/CT ranged from 9 to $70 \%$. Most studies used concomitant CT imaging or previous CT/MRI/ ultrasound for morphological comparison of the radiopharmaceutical uptake seen in the pancreas [8-13]. Malignancy findings were very rare in the absence of morphological 
Table 1 Basic study and patient characteristics of the included studies

\begin{tabular}{|c|c|c|c|c|c|c|c|c|c|}
\hline Authors & Year & Country & Study design & & $\begin{array}{l}\text { Numbers } \\
\text { of patients } \\
\text { included }\end{array}$ & $\begin{array}{l}\text { Patients with } \\
\text { pancreatic } \\
\text { NET }\end{array}$ & $\begin{array}{l}\text { Patients with } \\
\text { non-pancreatic } \\
\text { NET }\end{array}$ & $\begin{array}{l}\text { Average age } \\
\text { [range] }\end{array}$ & Male/female \\
\hline $\begin{array}{l}\text { Al-Ibraheem } \\
\text { et al. }\end{array}$ & 2011 & Germany & Retrospective & Monocentric & 43 & 3 & 40 & 64 [28-81] & NR \\
\hline $\begin{array}{l}\text { Castellucci } \\
\text { et al. }\end{array}$ & 2011 & Italy & Retrospective & Monocentric & 100 & 0 & 100 & NR [35-78] & $60 / 40$ \\
\hline $\begin{array}{l}\text { Jacobsson } \\
\text { et al. }\end{array}$ & 2012 & Sweden & Retrospective & Monocentric & 50 & 0 & 50 & 59 [14-88] & $26 / 24$ \\
\hline Krausz et al. & 2012 & Israel & Retrospective & Monocentric & 103 & 40 & 63 & 58.6 [16-89] & $50 / 46$ \\
\hline $\begin{array}{l}\text { Kunikowska } \\
\text { et al. }\end{array}$ & 2012 & Poland & Retrospective & Monocentric & 250 & NR & NR & $\begin{array}{l}55.5 \pm 14.1 \\
{[\mathrm{NR}]}\end{array}$ & $90 / 160$ \\
\hline Mapelli et al. & 2014 & UK & Retrospective & Monocentric & 138 & 38 & 100 & $\begin{array}{c}55.8 \pm 15.4 \\
{[20-84]}\end{array}$ & $77 / 61$ \\
\hline
\end{tabular}

NET neuroendocrine tumour, $N R$ not reported

lesions or abnormalities at the time of the SSTR PET/CT $[11,12]$. All studies used both visual and quantitative assessment of the uptake seen in the UP with a wide heterogeneity across studies for the methodology used. Interestingly, in one study, SSTR PET/CT was performed during follow-up without demonstration of malignancy in the site of physiological radiopharmaceutical uptake in the pancreas [9].

\section{Quantitative analysis}

The pooled prevalence of physiological uptake in the pancreatic head and UP at SSTR PET/CT, taking into account 684 PET/CT scans, was 34.1\% (95\% CI 19.5-48.7\%) (Fig. 2). A significant heterogeneity across studies was found by the $I^{2}$ index (95\%), whereas a significant publication bias was excluded by the Egger's test. Unfortunately, due to the limited number of available articles, subgroup analyses to statistically explore the heterogeneity could not be performed.

\section{Discussion}

The increase in SSTR PET/CT scans prompt to a better understanding of physiological uptake and pitfalls to minimize the number of unnecessary follow-up investigations [1-4]. In that setting, the physiological radiopharmaceutical uptake in the pancreatic head and UP on SSTR PET/ CT should be recognized and further investigations should only be done in case of a strong suspicion of malignancy especially in patients with NETs (Fig. 3). We performed a systematic review and meta-analysis on the prevalence of the physiological radiopharmaceutical uptake in the pancreatic head and UP on SSTR PET/CT to increase the statistical power compared to single-centre studies, hence providing evidence-based data for the nuclear medicine physician in routine practice [8-13]. Though the prevalence of physiological uptake in the pancreatic head and UP varied across studies, it was relatively frequent, seen in up to $70 \%$ of the patients in the study by Jacobsson et al. [10]. Most of the studies except for one included NETs patients, which might induced a bias especially since no direct comparison to a control group without history of NETs was done [8-13].

Regardless, we should underscore that there was a wide heterogeneity in the methodology across studies, as reported visual and quantitative assessment criteria varied significantly [8-13]. Indeed, not all studies had a clear definition of what should be considered as an increased uptake in the UP by visual assessment. Only some of the studies used a reference value for the quantitative assessment, which might have lead to variation in the accurate prevalence of physiological findings in the pancreas on SSTR PET/CT. For instance, in the study by Jacobsson et al., there was no distinction according to the uptake pattern of the UP on visual analysis whereas Al-Ibraheem et al. distinguished between focal and irregular pattern of uptake $[8,10]$. Other factors that might interfere with a correct assessment of prevalence of physiological uptake in the pancreatic head and UP on SSTR $\mathrm{PET} / \mathrm{CT}$ are the different radiotracers used in the studies included in this systematic review $\left({ }^{68} \mathrm{Ga}\right.$-DOTATATE, ${ }^{68} \mathrm{Ga}$ DOTATOC or ${ }^{68} \mathrm{Ga}$-DOTANOC) [3, 8-14]. Interestingly, it seems that the reported prevalence was higher in the studies using ${ }^{68} \mathrm{Ga}$-DOTATOC as a radiotracer in comparison to other tracers [8-14]. Further investigations comparing similar population of patients undergoing different SSTR radiotracers might help determine the impact of the radiotracer on prevalence of UP physiological uptake. The delay between radiotracer injection and PET/CT acquisition might also have played a part [3, 8-14]. Indeed, we found that even for studies using the same radiotracers, the delay between radiotracer injection and PET/CT acquisition varied which 


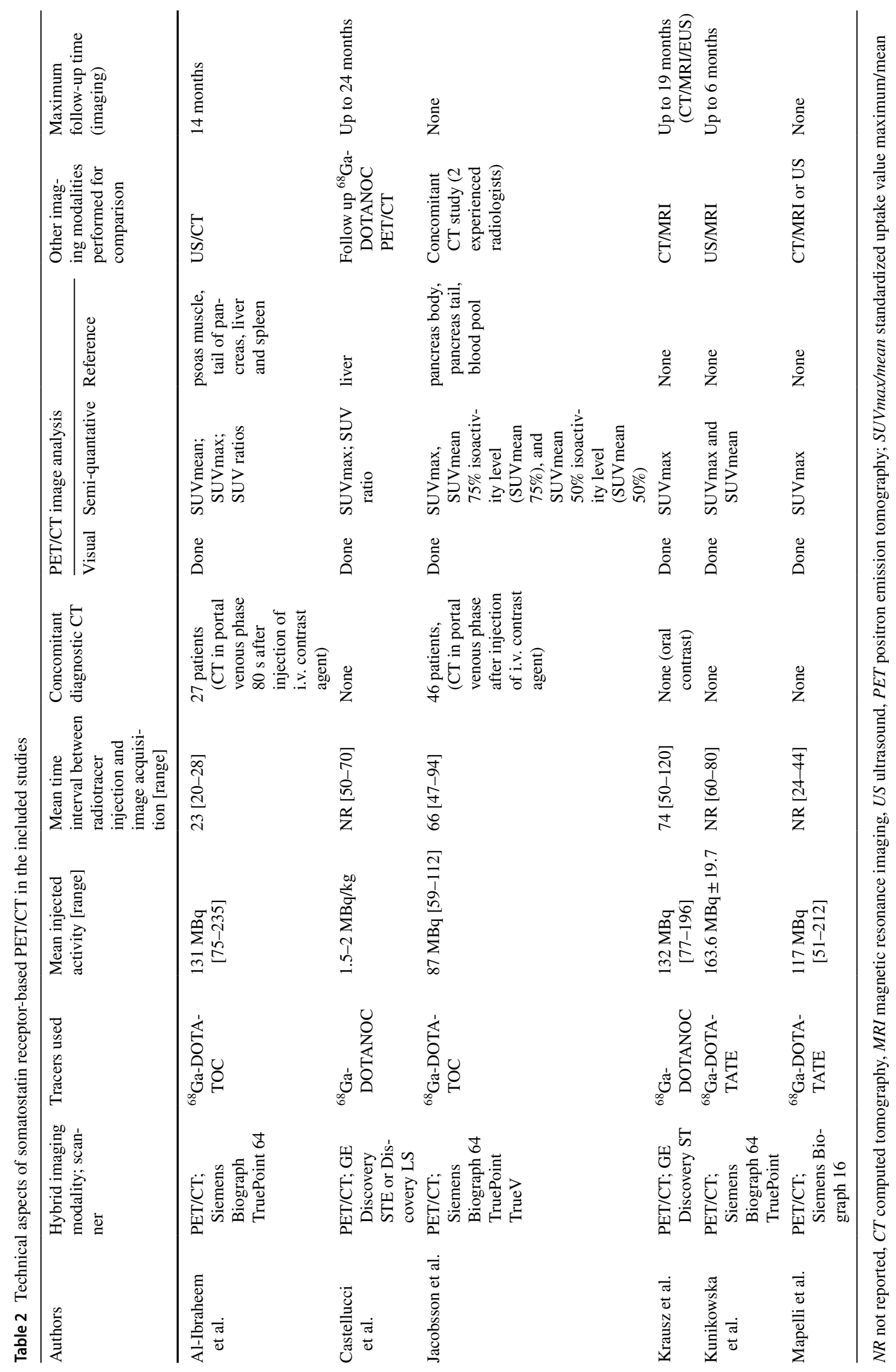


Table 3 Physiological uptake in the pancreas at somatostatin receptor-based PET/CT in the included studies

\begin{tabular}{|c|c|c|c|c|c|c|}
\hline Authors & $\begin{array}{l}\text { Incidental physi- } \\
\text { ological uptake in } \\
\text { the pancreas }\end{array}$ & $\begin{array}{l}\text { SUV values of inci- } \\
\text { dental findings in the } \\
\text { pancreas (range) }\end{array}$ & $\begin{array}{l}\text { Comparison to } \\
\text { morphological } \\
\text { imaging }\end{array}$ & $\begin{array}{l}\text { Somatostatin } \\
\text { receptor-based } \\
\text { PET/CT performed } \\
\text { at follow-up }\end{array}$ & $\begin{array}{l}\text { Somatostatin } \\
\text { receptor-based } \\
\text { PET/CT performed } \\
\text { at follow-up }\end{array}$ & $\begin{array}{l}\text { Pathological } \\
\text { confirmation }\end{array}$ \\
\hline Al-Ibraheem et al. & $20 / 43$ & $\begin{array}{l}\text { SUVmean }=5.8 \pm 7.6 \\
(1.5-39.3) ; \text { SUV- } \\
\max =9.8 \pm 12.5 \\
(2.4-62.2)\end{array}$ & $\begin{array}{l}\text { No direct compari- } \\
\text { son }\end{array}$ & No & No & Yes \\
\hline Castellucci et al. & $31 / 100$ & $\begin{array}{l}\text { SUVmax focal } \\
\text { uptake }=12.6 \pm 2.2 \\
\text { SUVmax diffuse } \\
\text { uptake }=5.0 \pm 1.6\end{array}$ & $\begin{array}{l}\text { Previous CT or } \\
\text { MRI showing } \\
\text { normal pancreatic } \\
\text { density without } \\
\text { evidence of } \\
\text { disease }\end{array}$ & $\begin{array}{l}\text { Yes, with confirma- } \\
\text { tion of physi- } \\
\text { ological uptake }\end{array}$ & $\begin{array}{l}\text { Yes, with confirma- } \\
\text { tion of physi- } \\
\text { ological uptake }\end{array}$ & No \\
\hline Jacobsson et al. & $35 / 50$ & $\begin{array}{l}\text { SUVmax }=9.2 \pm 2.9 \\
\text { SUVmean } \\
75 \%=7.8 \pm 2.6 \\
\text { SUVmean } \\
50 \%=6.0 \pm 2.0\end{array}$ & $\begin{array}{l}\text { No suspicion of any } \\
\text { pathology of the } \\
\text { pancreatic head at } \\
\text { the concomitant } \\
\text { CT study }\end{array}$ & No & No & No \\
\hline Krausz et al. & $38 / 103$ & $\begin{array}{l}\text { SUVmax }=6.6 \pm 2.2 \\
\quad(2.2-12.6)\end{array}$ & $\begin{array}{l}\mathrm{CT}, \mathrm{MRI} \text { and } \\
\text { ultrasound only in } \\
36 \text { cases }\end{array}$ & No & No & No \\
\hline Kunikowska et al. & $41 / 250$ & SUVmax $=9.2 \pm 3.3$ & $\begin{array}{l}\text { CT, MRI and } \\
\text { ultrasound only in } \\
30 \text { cases }\end{array}$ & No & No & No \\
\hline Mapelli et al. & $13 / 138$ & $\begin{array}{l}\text { SUVmax }=6.4 \\
(2.1-17.9)\end{array}$ & Unclear & No & No & No \\
\hline
\end{tabular}

NR not reported, $C T$ computed tomography, MRI magnetic resonance imaging, PET positron emission tomography, SUVmax/mean standardized uptake value maximum/mean

\section{Prevalence of physiological uptake in the pancreas by using somatostatin receptor PET (all tracers)}

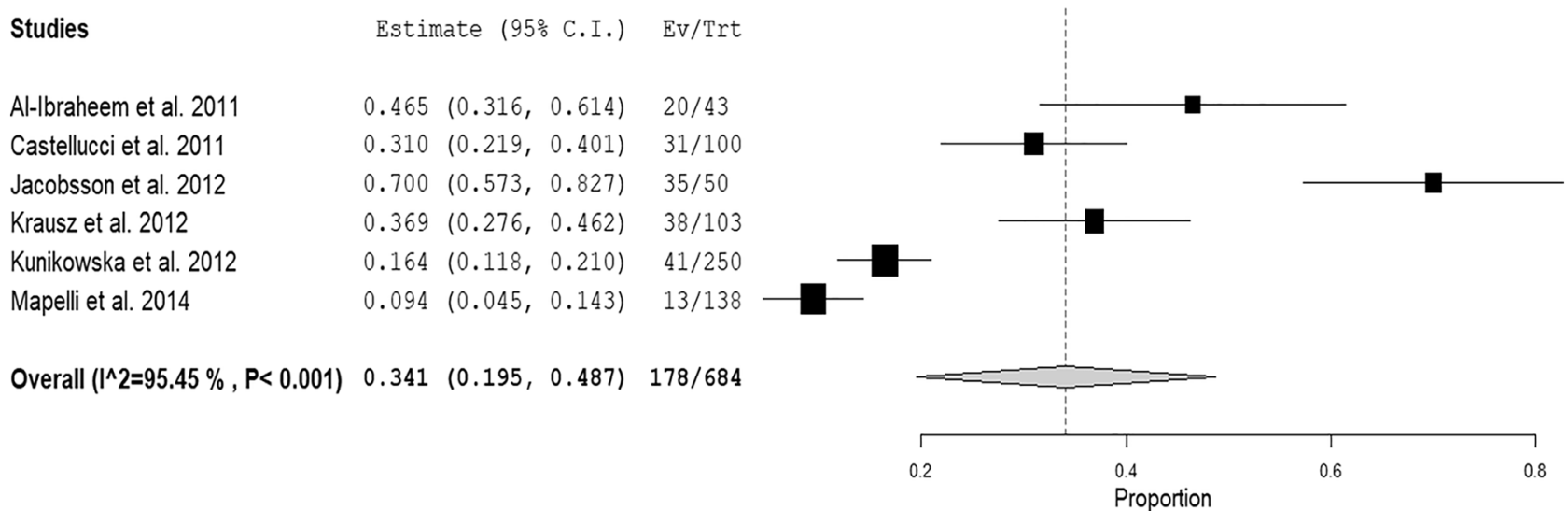

Fig. 2 Pooled analysis on the prevalence of physiological uptake in the pancreas at somatostatin receptor-based PET/CT

might be an additional a bias for a direct comparison of the prevalence of the physiological uptake of the UP between studies [8-14]. The lack of direct comparison between pancreatic uptake on SSTR PET/CT and morphological imaging (contrast-enhanced CT or MRI at time of PET/CT) is also problematic as NETs are known to be hyperarterialized and small tumors might not be seen on a standard low-dose CT [9, 11-13]. Moreover, follow-up was not available in some studies and pathological confirmation of suspicious physiological uptake in the pancreas on SSTR PET/CT was very 
Fig. 3 Somatostatin receptorbased PET/CT and contrastenhanced CT axial images showing an area of increased radiopharmaceutical uptake corresponding to a pancreatic neuroendocrine tumour in the uncinate process of the pancreas at CT images (yellow arrows) and an area of physiological radiopharmaceutical uptake in the uncinate process of the pancreas without abnormalities at CT images (white arrows)

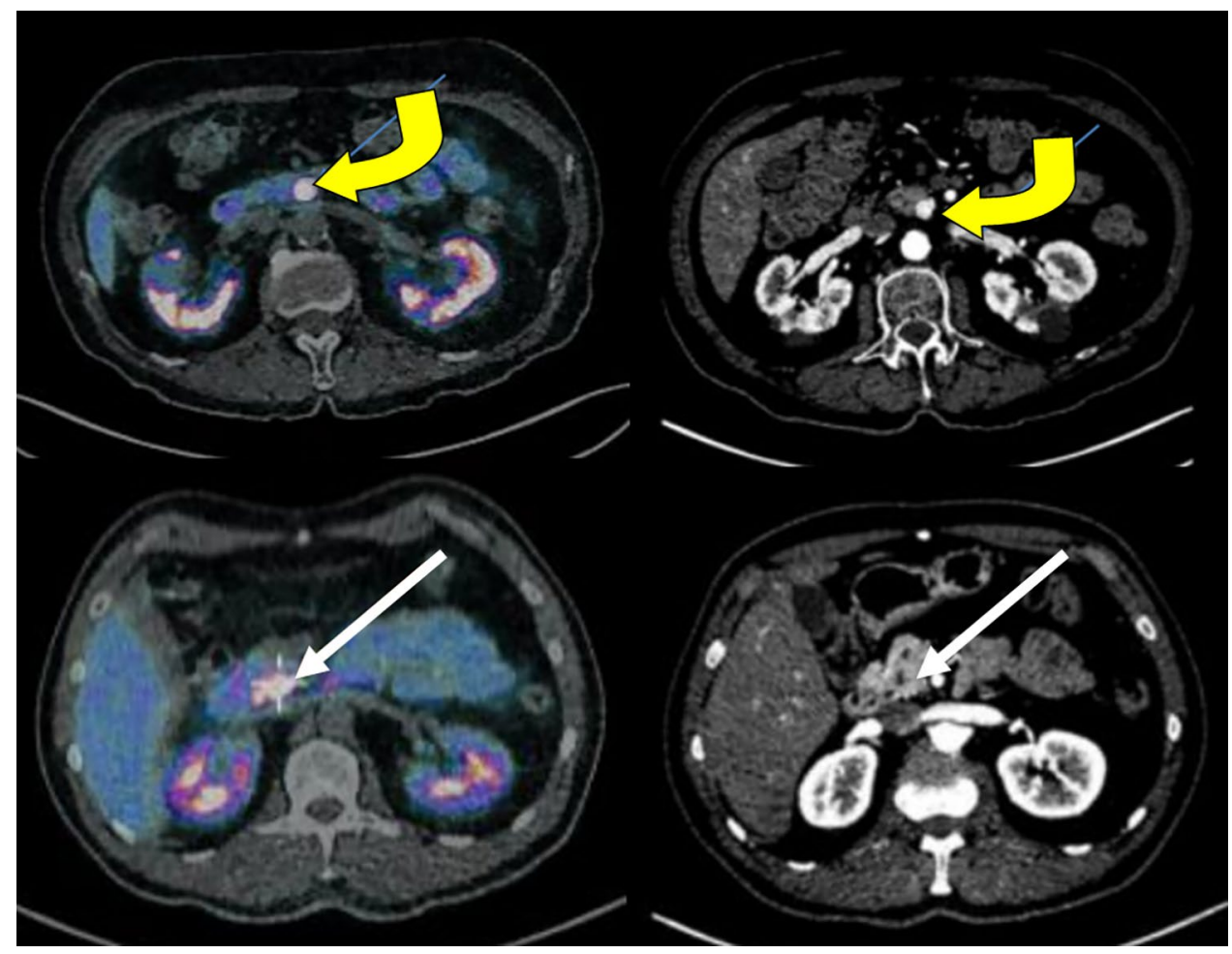

rare [8]. However, it is clear that increased uptake in the pancreatic head and UP on SSTR PET/CT with no morphological correlation seen on conventional imaging was rarely associated with malignancy during follow-up [11, 12].

Besides, more research is needed with new generation PET/CT tomographs as all the studies included in this systematic review were done using older generation PET/ $\mathrm{CT}$ tomographs. The introduction of next generations tomographs implemented with digital detectors and more performant reconstructions algorithms (such as Bayesianpenalized likelihood reconstruction or point spread function correction) might affect both visual and quantitative assessment of the uptake in the pancreatic head and UP at SSTR PET/CT $[15,16]$. Thus, original research studies on the impact of next generation silicon photomultiplier (SiPM) with time of flight PET/CT machines on the prevalence of this physiological finding are needed to assist the nuclear medicine physician in routine practice. The advent of PET/ MRI tomographs might also play a part in improving the characterization of radiopharmaceutical uptake in the UP as physiological at SSTR PET, with a better anatomical definition on the corresponding MRI images in comparison to low-dose CT.

Lastly, we should report several limitations in our review, which could limit the scope of our results. First, our selection and exclusion criteria lead to a very small number of original articles eligible for inclusion in this systematic review. Second, as previously mentioned, there was significant heterogeneity across studies in terms of patient population, PET radiotracers and protocols but also in image interpretation, which could have affected our analysis. Additionally, the quality of the six studies included is moderate, as they were single centre and retrospective [8-13]. Nonetheless, in our opinion, the strength of this mini-review was to highlight that physiological radiopharmaceutical uptake in the UP of the pancreas at SSTR PET/CT is frequent. Nuclear medicine physicians should recognize this finding a SSTR PET/CT to avoid unnecessary and costly additional investigations especially since this examination is becoming routine practice across institutions.

\section{Conclusion}

This systematic review showed that a physiological radiopharmaceutical uptake in the pancreatic head and UP on SSTR PET/CT is relatively frequent and should be acknowledged by nuclear medicine physicians interpreting these images especially in NETs patients as to avoid unnecessary and costly additional investigations. Moreover, next generation PET/CT scanners implemented with SiPM-based detectors and more performant reconstructions algorithms might increase the prevalence of this physiological finding and further investigations are needed to assist imaging interpretation. 
Funding Open Access funding provided by Università della Svizzera italiana.

\section{Declarations}

Conflict of interest The authors declare that they have no financial or non-financial competing interests.

Disclosure The authors declare no conflict of interest relevant to this article.

Ethical approval This article does not contain any studies with human participants or animals performed by any of the authors.

Open Access This article is licensed under a Creative Commons Attribution 4.0 International License, which permits use, sharing, adaptation, distribution and reproduction in any medium or format, as long as you give appropriate credit to the original author(s) and the source, provide a link to the Creative Commons licence, and indicate if changes were made. The images or other third party material in this article are included in the article's Creative Commons licence, unless indicated otherwise in a credit line to the material. If material is not included in the article's Creative Commons licence and your intended use is not permitted by statutory regulation or exceeds the permitted use, you will need to obtain permission directly from the copyright holder. To view a copy of this licence, visit http://creativecommons.org/licenses/by/4.0/.

\section{References}

1. Bodei L, Boni G, Paganelli G et al (2013) Neuroendocrine tumors. Nuclear Oncology. Springer 2013:491-520

2. Nissen NN, Kim AS, Yu R et al (2009) Pancreatic neuroendocrine tumors: presentation, management, and outcomes. Am Surg 75:1025-1029

3. Bauckneht M, Albano D, Annunziata S et al (2020) Somatostatin receptor PET/CT imaging for the detection and staging of pancreatic NET: a systematic review and meta-analysis. Diagnostics 10(8):598

4. Treglia G, Kroiss AS, Piccardo A et al (2018) Role of positron emission tomography in thyroid and neuroendocrine tumors. Minerva Endocrinol 43(3):341-355

5. Prasad V, Baum RP (2010) Biodistribution of the Ga-68 labeled somatostatin analogue DOTA-NOC in patients with neuroendocrine tumors: characterization of uptake in normal organs and tumor lesions. Q J Nucl Med Mol Imaging 54:61-67
6. Wittingen J, Frey CF (1974) Islet concentration in the head, body, tail and uncinate process of the pancreas. Ann Surg 179:412-414

7. Sadeghi R, Treglia G (2017) Systematic reviews and meta-analyses of diagnostic studies: a practical guideline. Clin Transl Imaging 5:83-87

8. Al-Ibraheem A, Bundschuh RA, Notni J et al (2011) Focal uptake of $68 \mathrm{Ga}$-DOTATOC in the pancreas: pathological or physiological correlate in patients with neuroendocrine tumours? Eur J Nucl Med Mol Imaging 38(11):2005-2013

9. Castellucci P, Ucha JP, Fuccio C et al (2011) Incidence of increased $68 \mathrm{Ga}$-DOTANOC uptake in the pancreatic head in a large series of extrapancreatic NET patients studied with sequential PET/CT. J Nucl Med 52(6):886-890

10. Jacobsson H, Larsson P, Jonsson C, Jussing E, Grybäck P (2012) Normal uptake of $68 \mathrm{Ga}$-DOTA-TOC by the pancreas uncinate process mimicking malignancy at somatostatin receptor PET. Clin Nucl Med 37(4):362-365

11. Krausz Y, Rubinstein R, Appelbaum L et al (2012) Ga-68 DOTANOC uptake in the pancreas: pathological and physiological patterns. Clin Nucl Med 37(1):57-62

12. Kunikowska J, Królicki L, Pawlak D, Zerizer I, Mikolajczak R (2012) Semiquantitative analysis and characterization of physiological biodistribution of 68Ga-DOTA-TATE PET/CT. Clin Nucl Med 37(11):1052-1057

13. Mapelli P, Tam HH, Sharma R et al (2014) Frequency and significance of physiological versus pathological uptake of $68 \mathrm{Ga}-$ DOTATATE in the pancreas: validation with morphological imaging. Nucl Med Commun 35(6):613-619

14. Bozkurt MF, Virgolini I, Balogova S et al (2017) Guideline for PET/CT imaging of neuroendocrine neoplasms with 68 Ga-DOTA-conjugated somatostatin receptor targeting peptides and 18 F-DOPA. Eur J Nucl Med Mol Imaging 44(9):1588-1601

15. Teoh EJ, McGowan DR, Schuster DM, Tsakok MT, Gleeson FV, Bradley KM (2018) Bayesian penalised likelihood reconstruction (Q. Clear) of 18F-fluciclovine PET for imaging of recurrent prostate cancer: semi-quantitative and clinical evaluation. Br J Radiol 91(1085):20170727

16. Ferretti A, Chondrogiannis S, Rampin L et al (2018) How to harmonize SUVs obtained by hybrid PET/CT scanners with and without point spread function correction. Phys Med Biol 63(23):235010

Publisher's Note Springer Nature remains neutral with regard to jurisdictional claims in published maps and institutional affiliations. 